International Journal of Social Science And Human Research

ISSN(print): 2644-0679, ISSN(online): 2644-0695

Volume 04 Issue 06 June 2021

DOI: 10.47191/ijsshr/v4-i6-04, Impact factor-5.586

Page No : 1250-1256

\title{
Recognition of the Victimizer and Its Application in Criminal Police Investigations
}

\author{
Hosein Sharifpour ${ }^{1}$, Mahdis Malekzadeh ${ }^{2}$, Sajjad Mohammadi $^{3}$, Sheida Taghadosi ${ }^{4}$ \\ ${ }^{1}$ Departmant of Prevention of Crime, Najja faculty member, Tehran, Iran \\ ${ }^{2}$ Faculty of Law and Political Sciences, University of Tehran, Iran \\ ${ }^{3}$ Faculty of Law and Political Sciences, University of Tehran, Iran \\ ${ }^{4}$ Faculty of Law, Islamic Azad University, Qaemshahr, Iran
}

\begin{abstract}
Over time, the study of the victimizer concept indicates the evolution of this concept and the emergence of four different tendencies in this field, which have been created in response to the offenders' needs. These four tendencies are 1- general victimizer, 2- criminal or reciprocal action, 3-critical victimizer and 4- legal victimizer. The fourth approach, the new method of the victimizer, aims to investigate the characteristics of the victimizer, the pattern of the victimizer, and the repetition of these patterns to achieve the criminal seminally. Rush to the aid of homicide investigations, police and detectives. Forensic victimizer against theoretical principle is an applied principle.

This stage of victimizer by adopting a new approach of misdemeanours while examining the normative and individualized offenders specific offences, drawing all the patterns of victimizer and discovering a list of comprehensive characteristics of the offender such as physical, biological, mental, social, educational, occupational and personality characteristics during the victimizer While estimating the criminality of the offender, it tries to create comprehensive standards for faster detection of similar crimes and also by identifying hidden and suspicious models of victimizer to help prevent crime. This approach by collecting preliminary information and forming a conscious profile for the victimizer is deliberate parts of the puzzle of personality, age, social, economic, cultural, etc. It also solves the victimizer, and considering and interpreting the statements and experience of certain offenders scientifically is trying to answer the questions.
\end{abstract}

KEYWORDS: victimizer, misdemeanours, criminal, police, suspicious

\section{INTRODUCTION}

As one of the tendencies of social sciences and analytical criminal sciences, victimizer is a large subject with several subcategories, some of which are theoretical and others practical. Victimizer's three main subcategories under titles 1- general victimizer, 2criminal victimizer or reciprocal action and 3. victimizer is critical. The first tendency, such as general victimizer, seeks to study individuals or groups that have suffered injuries or lost someone or something (Hoeve, 2009). In this type of victimizer, there is no difference between a person, a misdemeanour of a particular crime, a misdemeanour of cruelty in general, or a victim of natural disasters. Spohn and Holleran (2002) believe that this attitude, all offenders, including misdemeanours, victimizers, socio-political environments, natural environments, technology-industry, and even those who victimizer themselves. General victimizer seeks to identify and develop preventive measures to help the victimizer, in this tendency of demonologists, and to study the aetiology of the victimizer, seeking solutions to compensate. Criminal victimizer or misdemeanour of reciprocal action investigates the rate of victimizer participation in creating a crime. Issues such as illegal participation in the cause of the crime's disability through interaction with the offender, interaction between victimizer and society, and the role of the criminal offender in the criminal justice system are considered in this tendency of the victimizer. Like the previous tendency, misdemeanours who do not engage in reciprocity try to investigate the victimizer and develop solutions to provide benefits and protect the victimizer (Emler \& Reicher, 2004).

Critical victimizer emerged in response to the two forehands; in fact, critical victimizer seeks to question the victimizer processes and even reaction to these two. The essential principle of victimizer assumes that the theories and research methods of the mentioned tendencies are inadequate because generally, certain species the crimes and their victimizers are raised in these tendencies, which are more well-known and easier to understand, and this ultimately leads to their failure (Forgatch et al., 2009). This paper will delineate a precise concept between forensic victimizer and other tendencies and species, analyze the applications of this type of victimizer in criminal and police investigations, and the importance of paying attention to it in Iran. Thus, using 


\section{Recognition of the Victimizer and Its Application in Criminal Police Investigations}

analytical descriptive method and library tools, after reviewing victimizer conceptual transformation, investigating the objectives and application of forensic victimizer in crime detection.

\section{THE PROGRESS OF A VICTIMIZER CONCEPTUAL}

The course of the conceptual transformation of the victimizer from the historical point of view of the term victimizer was used to describe the individuals or animals that were to be sacrificed to thank God. In the 1991s, the term sacrifice was generally associated with the concept of injury or loss. The primary concepts of victimizer were founded not by criminologists and sociologists but by poets, writers and storytellers. The storytellers are Thomas D. Quince, Khalil Gibran, Aledes Huxley, Marcus D.S. and Franz Wurfel. Today, victimizer generally refers to the scientific study of the offenders and their relationships with criminals, research authorities, follow-ups, sentencing, execution of punishments, media and social movements. It is important to investigate where victimizer originated and how they developed. Therefore, exploring the role of victimizers in different periods of criminal justice history is essential.

Hollin and Kendrick (2008) acknowledge that in an era called the Golden Age, before the existence of written law and the establishment of states, there were laws such as that, in most of these laws, played a clear role in determining penalties for those affected by them or their property. Documentary historical reports indicate that in this period, personal punishment was the only solution to criminal phenomena. The offenders are actively and directly seeking retaliation or receiving damages from those who raped them. Explaining this in the form of a " victimizer justice system, against the criminal justice system," they say that in this period, the type of action against the attacker depends on the offender or his survivors. Although victimizer-thrust approaches to justice have been one of the earliest manifestations of the victimizer, they exist in many legal systems, especially those influenced by ancient religious thoughts. These approaches become problematic with population growth and the development of groups and families. This is in most cases partly due to crimes that do not harm or only harm a person (Sigda, 1999). Depending on the nature of the crime, it may be harmful to a family, tribe or culture. If the offender is not available for punishment, his/her relatives must take responsibility for the damage caused. Worse is the cases in which the next generations inherit any insults and injustices that the last generation has committed, so committing a crime can involve other people. Constant reprisals led to prolonged blood feuds between families or tribes. Ultimately, many have realized that although this promotes family, tribe, and even cultural loyalty, this kind of justice contributes little to resolving conflict. The notion that committing a crime against an individual means committing a crime against a family, tribe or society does not help to reduce the suffering and harm caused by the crime. This pattern of justice extends the damage caused by the original offence to those not directly involved in this crime. At the same time, following subsequent reprisals leads to repeated cycles of victimizer (Ahmed, 2013).

It should be noted that criminal misdemeanour-centred justice worsens the situation instead of serving the victimizer. One of the main characteristics of the golden age of victimizer is that the victimizer is the centre of claims. However, due to the lack of progress of the proving system, the misdemeanour claim against the criminal was expressed and proven in traditional ways, thus, the failure to provide definitive evidence and the awarding of errors in the possibility of wrongdoing in accusing the person. Accusations led to generations of vengeance and the teaching of hatred from generation to generation (Lalik, 2017). The list of problems related to the golden age of the victimizer is very long. The emergence of locally organized governments and the development of the legal and criminal system lead to the emergence of rounds in which criminals are forgotten due to the forgetting of the main person affected by abnormal behaviour and the taking of all rights related to the dispute by the representative (Bigo, 2002).

The beginning of the dark or black era of victimizer is tied to the emergence of states. The emergence of governments is itself a sub-result of creating more sustainable economic systems, which occurred through the expansion of urbanization and the Industrial Revolution and the increase in the power of the Roman Catholic Church. As families move from villages to cities, neighbourhoods lack character and old systems such as culture and kinship can no longer be continued. In these criminal-centred justice systems, the crime occurs incrementally against a misdemeanour or a victimizer family or country. Ultimately, the focus is on the rights and punishment of the offender against misdemeanour compensation or the granting of rights. Subsequently, with the emergence and expansion of official criminal justice systems, illegal participation became less and less evidenced and informed to provide information to the police (Von Lampe, 2006).

The development of official law enforcement by police, courts, and the prison system has increased the desire to remove misdemeanours from litigation and focus on criminal punishment over the past centuries. In most parts of the world, the criminal justice system forgets the criminals' vassal and desires or interests. This growing trend is that new criminal justice systems do not necessarily seek to help the criminal. In this relatively long period, the government and its representative have been considered the principal owners of criminal litigation. The role of a crime has been reduced to the extent of a witness or sometimes a confirmer or rejector of an illegal claim. Still, since the middle years of the twentieth century, due to critical studies on the criminal process, we are once again witnessing attention to the victimizer and rights (Tyler et al., 2015).

The re-emergence of a misdemeanour occurred between 1950 and 1960 when few people paid attention to neglecting the crime as the principal offender. These experts have noted the excessive reduction in the possibility of victimizer intervention during the 


\section{Recognition of the Victimizer and Its Application in Criminal Police Investigations}

dispute and forgetting the needs and rights of the criminals and fought for their re-rights. In a short period, this became a general agreement among different groups, including journalists, sociologists, and the main drags of the criminal justice system, with the special request that the needs and demands of criminals, as forgotten, of the criminal justice process should once again be taken into consideration by criminal justice systems (Cullen, 2013). Thus, the misdemeanour was once again considered; however, the victimizer of addressing the needs of the offenders and relieving the harm they suffered a reversal route due to the provocative role of the offender in the process of committing a crime. Thus, victimizer began to grow, expand and diversify attitudes continuously. Therefore, during the last 52 years, victimizer has changed radically. The primary victimizer was essentially theoretical, which was almost exclusively related to causal explanations of the crime and the role of the victimizer. Its main focus was on investigating the characteristics of the offenders, their relationships, and the offenders' interaction with the perpetrators (Morash, 2006).

This theoretical framework was the guide of the first study conducted in the early days of victimizer by Alan Berger, Wolfgang, Amir, Normando, Curtis, Silverman, and Fattah. The Feminist Movement led to the restoration of the rights of the criminals. This movement fiercely defended the victims of crimes of rape the beaten weights, causing the most significant amount of sympathy and compared to a group of people in society who were primarily deprived of social rights. A new centre of attention to victimizer was formed that helped and assisted the victims of the crime while reducing their plight, cleared and confirmed their rights. A political movement arose, and victimizer was increasingly defined and recognized by its functional components (Kukino, 2015).

The applied section of victimizer has become more applicable with the advent of the forensic victimizer. The method of studying misdemeanours in forensic victimizer is different from conventional victimizer in criminology. It uses individual reviews and normative to analyze crime victims and pyramidal conditions to achieve the offender. Despite conventional victimizer in criminology, forensic victimizer is an applied palate tendency used by police and other criminal investigation and crime detection activists. The primary purpose of this tendency is to cohere criminal investigations, reduce time-wasting using similarities of victimizer patterns to detect crime and criminality. Another goal of legal victimizer is to lower the rate of wrongful convictions of the judicial system due to testimony affected by the excitement of the offenders, especially the offenders of violent crimes (Siegel $\&$ Welsh, 2016).

\section{Legal misdemeanour}

The tendency toward applying victimizer in recent decades has led to using this approach in criminal police investigations. In the study of victimizers, like any other subject, there are two main approaches to research and knowledge acquisition. The first approach is normative knowledge, which investigates and analyses the comprehensive and comprehensive rules on a particular subject (here is a misdemeanour). The second approach knowledge is pure study, which includes examining individuals and their characteristics (Thornberry \& Krohn, 2000).

Normative studies seek to find subscriptions, and individual studies aim to find differentials. In forensic victimizer, using normative and particular methods, general and personal characteristics of victimizers and victimizer processes are identified. The primary purpose of Franger's victimizer is to study and determine the unique features of specific victimizers, resulting in particular crimes, injuries or losses; While the main objective of normative victimizer is to collect general, type and shared characteristics among victimizer groups, discover victimizer patterns, why the desirability of repeating these patterns, predict the behavioural and intellectual patterns of victimizers willing to cause victimizer (Farrington et al., 2013). These characteristics are abstract in the sense that they are not necessarily probable. Forensic victimizer revolves around the study of actual victimizer and the necessity of information regarded in scientific police and forensic medicine processes. Still, normative victimizer details may develop theories or provide a fundamental inference point with appropriate warnings. The law-wise study best covers the general knowledge of criminal groups that can be applied to a particular offender have or don't have (Ribaux et al., 2016).

Forensic victimizer by individually examining the offenders of specific crimes, drawing all the victimizer patterns and discovering a list of comprehensive victimizer characteristics such as physical, biological, mental, social, educational, occupational and personal characteristics. At the time of the victimizer, his attempts to estimate the criminal are comprehensive standards for faster detection of similar crimes and by identifying the hidden and suspicious models of victimizer to help prevent the crime. Forensic victimizers, by collecting preliminary information and forming a conscious profile for the victimizer, are deliberate parts of the puzzle of personality, age, social, economic, cultural, etc. It also solves the victimizer (Ossorio \& Duster, 2005).

\section{Objectives}

As mentioned earlier, forensic victimizer seeks to investigate, study and interpret evidence related to a particular misdemeanour to answer questions related to the stage of crime detection, finding the offender and increasing information about how and why the crime was committed, as well as the prevention of misdemeanours. In many cases, information related to a misdemeanour is used as a traffic light to guide victimizers or victimizers' identification and characteristics. In some cases, the information obtained in forensic misdemeanour is used to evaluate the accuracy or inaccuracy of the misdemeanour claim about the victimizer. Misdemeanour law is applicable in the following area:

1. Investigation of victimizer status. 


\section{Recognition of the Victimizer and Its Application in Criminal Police Investigations}

2. Acceptance or rejection of misdemeanour statements.

3. Investigation of the nature and extent of victimizer at risk of injury or loss.

4. Finding the motive for committing a crime.

5. Discovery of the method of committing a crime.

6. Helping to ask essential questions to conduct local affidavits and reports and ask questions from the informants or other offenders.

All of these cases are very important in crime detection and inspection. All of these cases are very important in crime detection and assessment. By focusing on its considerations, legal victimizer can also check the conformity of witnesses' testimony or the defendant's confession or misdemeanour claims, as one of the most reliable cases in the hearings, reviewing the misdemeanour reports trial, in particular, the cases mentioned above.

\section{Application of victim identification}

One of the essential uses of victimizer is to draw a criminal profile and find his motives in committing a crime. One of the most critical uses of victimizer is to remove a criminal profile and find his reasons for committing a crime. Victimizer characteristics as pieces of the puzzle identify outstanding personality and demographic factors such as age, sex, height, weight, a possible response to why the crime was committed. In particular, the procedure is used in crimes such as Burglary, incidental sexual assaults by foreign attackers, acts of the street and non-domestic violence, and other crimes in which a misdemeanour for a misdemeanour is an unfamiliar and unknown person. Thus, the crime scene, the characteristics of the misdemeanour and why the misdemeanour occurred, the direction of detectives' movement, and the discoverers of the crime to reach the unknown offender (Gunn et al., 2014). In this approach, all information related to the victimizer is considered necessary to the legal victimizer. No points regarding victimizer should be hidden, whereas the periods from which it is referred to as the dark period of neglecting the victimizer. In addition to the complete disregard for the rights and needs of the offender, the characteristics and manner of victimizers, except for the influence of the board by the representative of the state in court or the prosecutor or the attorney of the accused or the misdemeanour was not considered. In this approach, the personality, body, soul, victimizer psyche is examined as a crime scene. Victimizer and motive characteristics are identified through the charms of different victimizer characters (Neubauer \& Fradella, 2018).

Investigating the significant relationship between victimizer and committing a crime is the key to answering many vital questions in the criminal investigation phase. The role of victimizer in self- victimizer is one of the most critical issues under investigation. In this regard, paying attention to the level and extent of exposure to victimizer is of particular importance (Walters, 2015). For example, a misdemeanour lifestyle can increase the likelihood of victimizer in several ways:

- The previous dispute between the perpetrator and the misdemeanour.

- Socializing and living among actual and potential criminals

- showing their weaknesses and vulnerabilities to existing and potential criminals

- Also, the tempting display of sybils or the triggering of a crime, for example, may have or features of a misdemeanour. victimizer lifestyle factors can affect the damage to the offender in several ways:

- By creating a conflict with the perpetrator by increasing the presence of misdemeanours around criminals or those who are susceptible to crime,

- By increasing the criminals' understanding of the vulnerability of the offender.

- Incitement and temptation to achieve the crime.

According to a criminology theory, crime occurs in a time and place where the opportunity to commit a crime is available. People may be more prone to misdemeanours based on their lifestyles. Depending on their prevalence and severity, many other factors risk exposure to misdemeanours increases, including drug use, impulsivity, depression, anger, etc. To evaluate the lifestyle of a particular offender, lifestyle factors should be examined to determine how these factors specifically help the person be exposed to injury and misdemeanour. For example, the offenders' lifestyle can be divided into three categories: offenders exposed to high damage, offenders exposed to joint injuries, and offenders in the exposure to injury were moderately divided (Siegel, 2015).

Victimizer lifestyle and victimizer conditions are two independent issues and should be evaluated separately. If this separation does not occur, it will lead to incorrect identification of the actual victimizer and the impossibility of citing evidence; this separation and investigation are independent of the duties of forensic misdeeds. This separation and analysis are independent of the responsibilities of forensic misdeeds. In addition, forensic misdemeanours have a significant obligation to ensure that the conditions of the misdemeanour have been investigated in a criminal record or not. This should be done before the conclusion of the preparation of the victimizer characteristics. If the conditions of the misdemeanour in the reports presented are biased or incomplete, then the actual circumstances of a crime will not be revealed. Legal victimizers must educate the vigilantes of these issues to prevent errors and abuses through realist education and impartiality (Tolan et al., 2018). 


\section{Recognition of the Victimizer and Its Application in Criminal Police Investigations}

\section{Psychological victimizer conditions}

The victimizer response to violent crimes varies from person to person. Suppose it is impossible to predict how a crime will behave. In that case, it is possible to turn a misdemeanour into a dangerous offender if the psychological conditions of the offender are measured. The appropriate response is received, the process of passing the victimizer is usually the case. It consists of three steps: 1: Acting based on the initial effect of attack 2: attempting to rebuild itself 3: Reorganization itself to return to daily activities of life,

However, ignoring the psychological conditions of the victimizer sometimes leads to very unconventional and damaging behaviours for the community adjacent; these behaviours change from aggressive actions towards themselves to others, to persons and equipment, and so on. With a careful look at the psychological conditions of the offender, forensic victimizer provides comprehensive and complete information to social and psychological workers to take appropriate measures. However, despite the generally numerous attempts at natural misdemeanours and accidents, criminal offenders are less considered by criminal justice systems than this; the pathology of the natural reactions of criminals indicates the syndromes used to describe these injuries. Some of these syndromes include post-traumatic stress disorder syndrome, beating syndrome, rape syndrome and commission syndrome. Attention to the mental disorders of the offender, especially in his subsequent testimonies in court, should be taken into consideration and notified to the judge before the jury is present; Sometimes, disregarding these cases causes unfairness of victimizer behaviour and consequently distorts the administration of justice, so in court, evidence of these mental disorders should be used as evidence to prove that the criminal has psychological problems. Sometimes paying attention to these disorders is essential to detect false claims of victimizer (Tomczak, 2010). Individuals provide false reports of misdemeanours for various reasons, such as expressing empathy, gaining profits, retaliating, hiding crime, etc. Although many studies have been conducted in this regard, scientific literature in this field is still very limited. Since there are credible scientific studies and minimal words, the statistics and rates are often unreliable. Unfortunately, experienced researchers and officials sometimes accept a misdemeanour claim without due diligent investigations, which may be due to incorrect policy in the face of misdemeanours, unconscious and compassionate advocacy, or lack of awareness about the power of destruction and the adverse effects of misdemeanour reports (Palmiotto, 2012).

\section{Domestic victimizer}

Domestic violence is more than just physical damage. There are various behaviours in domestic violence that physical trauma is just one of the ways to inflict emotional trauma. Seven types of abuses often occur in domestic violence: rejection, character destruction, threats and intimidation, social isolation, exploitation, emotional insensitivity, and imprisonment. In many cases, criminal offenders or domestic abusers are unaware of their victimizer, so failure to express it causes many parts of the fact to remain neglected in criminal investigations; sometimes, identifying these home victimizer leads to the discovery of essential details and effectiveness in criminal investigations (Neubauer \& Fradella, 2018).

\section{Ambush victimizer}

Repeated harassment and constant threats of one person by another are known as commissure. The offenders of the camouflage have a wide range, from strangers and acquaintances and celebrities to psychologists. Comorbid offenders experience a variety of psychological conditions, from post-traumatic stress disorders to general anxiety and listening. Combing is a practical and significant social crime and occurs with more community than other crimes, including murder. However, sometimes a combination can lead to murder or rape. Only by understanding the offenders of the commissary and the victimizer processes of these crimes can we know the general nature of the crime and the best way to deal with it (Kukino, 2015).

\section{In the court}

In criminal courts, the prosecution serves the state's interests and not the misdemeanour, so the role of the misdemeanour in court is not merely to cooperate with the prosecutor. Still, the criminals help the judge create some aspects of the crime through their evidence of harm or other relevant evidence. In criminal courts, the prosecution serves the state's interests and not the misdemeanour, so the role of the misdemeanour in court is not merely to cooperate with the prosecutor. Still, the criminals help the judge create some aspects of the crime through their evidence of harm or other relevant evidence. Misdemeanour information and related behaviours can affect the proving value of evidence. Forensic victimizer can play an essential role in the legal process through the practical and purposeful interpretation of misdemeanour information. As mentioned earlier, this can be done in various ways, such as considering claims. False victimizer, attention to the psychological conditions of the offender, adaptation of victimizer characteristics to victimizer conditions, etc. (Kohler-Hausmann, 2014).

\section{In preventing the wrongful conviction}

The rate of wrongful convictions is not low, and this issue has existed in the past and is not a new phenomenon. The rate of criminal convictions discovered in the United States became apparent in 1980, and the pace was subversives that could no longer be denied or ignored. The main reasons for issuing wrongful convictions are blaming eyewitnesses, legal errors, judicial errors, deception. Forensic victimizers have warned about this issue and suggested a scientific method with practical standards that leads to fair and reliable judgments and refrain from accepting unrealistic and biased reports and testimonies (Parkes \& Cunliffe, 2015). 


\section{CONCLUSION}

Forensic victimizer has recently led to the study of the victimizer, which is essential both in recognizing and drawing the criminal half of the criminal offender and finding the causes of victimizer and prevention of it, as well as in the trial process and discovering the cause of guilt or innocence of the criminal. Statutory victimizer by careful examination of the status, characteristics and personality of the offender following the victimizer's seminal homicide, acceptance or rejection of misdemeanour statements, investigation of the nature and extent of the misdemeanour arresting a crime motive, discovering the way a criminal was found, helping to raise essential questions for conducting local affidavits and reports, and questioning other informants or misdemeanours to speed up criminal investigations and other hidden forms of victimizer seek to prevent the crime. Thus, in addition to its importance in criminal investigations, this approach can also help find the truth and bring justice to the court at the stage of proving the case. However, despite the new process, which has been recognized in some Western countries at least since the beginning of the third millennium, has been taught in universities and used by experienced forensic criminals in the criminal research phase, it has not appeared in Iran and many other countries, even in the literature related to criminal science. However, familiarity with the principles and rules governing this approach can benefit the criminal investigation phase. While increasing the process of discovery and investigation, it can prevent the consequences such as accepting false claims of victimizer due to lack of proper recognition of the reality of victimizer or issuing wrongful verdicts.

\section{REFERENCE}

1) Hoeve, M., Dubas, J. S., Eichelsheim, V. I., Van der Laan, P. H., Smeenk, W., \& Gerris, J. R. (2009). The relationship between parenting and Delinquency: A meta-analysis. Journal of abnormal child psychology, 37(6), 749-775.

2) Spohn, C., \& Holleran, D. (2002). The effect of imprisonment on recidivism rates of felony offenders: A focus on drug offenders. Criminology, 40(2), 329-358.

3) Emler, N., \& Reicher, S. (2004). Delinquency: Cause or consequence of social exclusion? In Social psychology of inclusion and exclusion (pp. 229-260). Psychology Press.

4) Forgatch, M. S., Patterson, G. R., Degarmo, D. S., \& Beldavs, Z. G. (2009). Testing the Oregon delinquency model with a 9-year follow-up of the Oregon Divorce Study. Development and Psychopathology, 21(2), 637-660.

5) Hollin, C., \& Kendrick, D. (2008). Managing Behavioural Treatment: Policy and Practice for the Delinquent Adolescent. Routledge.

6) Sigda, K. B. (1999). Conduct problems among younger siblings of delinquent adolescents: Relationship quality and delinquency consequences as contexts for learning processes. The University of North Carolina at Chapel Hill.

7) Ahmed, A. (2013). The thistle and the drone: how America's war on terror became a global war on tribal islam. Brookings Institution Press.

8) Lalik, K. (2017). The Continuity of Settlement of Social Feuds among Kurds in the Kurdistan Region: The Case of Mektebî Komellayetî. Anthropology of the Middle East, 12(2), 92-107.

9) Bigo, D. (2002). Liaison officers in Europe: New officers in the European security field. In Issues in transnational policing (pp. 81-113). Routledge.

10) Von Lampe, K. (2006). The interdisciplinary dimensions of the study of organized crime. Trends in Organized Crime, 9(3), 77-95.

11) Tyler, T. R., Goff, P. A., \& MacCoun, R. J. (2015). The impact of psychological science on policing in the United States: Procedural justice, legitimacy, and effective law enforcement. Psychological science in the public interest, 16(3), 75-109.

12) Cullen, F. T. (2013). Rehabilitation: Beyond nothing works. Crime and justice, 42(1), 299-376.

13) Morash, M. (2006). Understanding gender, crime, and justice. Sage.

14) Kukino, S. E. (2015). Juvenile Transfer to Adult Criminal Court: Why Transfer is Not the Best Method in Addressing Juvenile Delinquency.

15) Siegel, L. J., \& Welsh, B. C. (2016). Juvenile Delinquency: The core. Cengage Learning.

16) Thornberry, T. P., \& Krohn, M. D. (2000). The self-report method for measuring delinquency and crime. Measurement and analysis of crime and justice: Criminal justice, 4.

17) Farrington, D. P., Piquero, A. R., \& Jennings, W. G. (2013). Offending from childhood to late middle age: Recent results from the Cambridge study in delinquent development. Springer Science \& Business Media.

18) Ribaux, O., Crispino, F., Delémont, O., \& Roux, C. (2016). The progressive opening of forensic science toward criminological concerns. Security Journal, 29(4), 543-560.

19) Ossorio, P., \& Duster, T. (2005). Race and genetics: controversies in biomedical, behavioural, and forensic sciences. American Psychologist, 60(1), 115.

20) Gunn, J., Taylor, P., \& Hutcheon, I. D. (2014). Forensic psychiatry: clinical, legal and ethical issues. CRC Press.

21) Neubauer, D. W., \& Fradella, H. F. (2018). America's courts and the criminal justice system. Cengage Learning. 


\section{Recognition of the Victimizer and Its Application in Criminal Police Investigations}

22) Walters, G. D. (2015). Proactive criminal thinking and the transmission of differential association: A cross-lagged multiwave path analysis. Criminal Justice and Behavior, 42(11), 1128-1144.

23) Siegel, L. J. (2015). Criminology: Theories, patterns, and typologies. Cengage Learning.

24) Tolan, P., Henry, D., Schoeny, M., \& Bass, A. (2008). Mentoring interventions to affect juvenile Delinquency and associated problems. Campbell Systematic Reviews, 4(1), 1-112.

25) Tomczak, V. M. (2010). The impact of emotional intelligence on substance use and Delinquency in a college sample: a comparison of emotional intelligence traits versus abilities (Doctoral dissertation, University of Alabama Libraries).

26) Palmiotto, M. J. (2012). Criminal investigation. CRC Press.

27) Kohler-Hausmann, I. (2014). Managerial justice and mass misdemeanours. Stan. L. Rev., 66, 611.

28) Parkes, D., \& Cunliffe, E. (2015). Women and wrongful convictions: concepts and challenges. Int'l JL Context, 11, 219. 